\title{
Predictors of complications in gynaecological oncological surgery: a prospective multicentre study (UKGOSOC_UK gynaecological oncology surgical outcomes and complications)
}

R lyer ${ }^{1,13}$, A Gentry-Maharaj ${ }^{1,13}$, A Nordin ${ }^{2}$, M Burnell ${ }^{1}$, R Liston ${ }^{1}$, R Manchanda ${ }^{1}$, N Das ${ }^{3}$, R Desai $^{1}$, R Gornall $^{4}$,

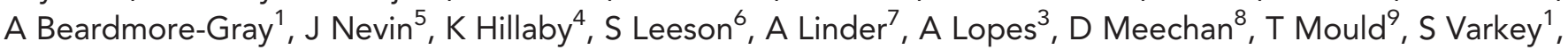
A Olaitan ${ }^{9}$, B Rufford ${ }^{7}$, A Ryan ${ }^{1}$, S Shanbhag ${ }^{10}$, A Thackeray $^{8}$, N Wood ${ }^{11}$, K Reynolds ${ }^{12}$ and U Menon ${ }^{*}, 1$

${ }^{1}$ Gynaecological Cancer Research Centre, Department of Women's Cancer, Institute for Women's Health, University College London, 1st Floor Maple House, 149 Tottenham Court Road, London W1T 7DN, UK; ${ }^{2}$ National Cancer Intelligence Network Gynaecology Clinical Reference Group, 5th Floor, Wellington House, 133-155 Waterloo Road, London SE1 8UG, UK; ${ }^{3}$ Department of Gynaecological Cancer, Royal Cornwall Hospitals NHS Trust, Truro, Cornwall TR1 3LJ, UK; ${ }^{4}$ Department of Gynaecological Oncology, Cheltenham General Hospital, Sandford Road, Cheltenham, Gloucestershire GL53 7AN, UK; ${ }^{5}$ Pan Birmingham Gynaecological Cancer Centre, Birmingham City Hospital, Dudley Road, Birmingham, West Midlands B18 7QH, UK; ${ }^{6}$ Department of Obstetrics and Gynaecology, Betsi Cadwaladr University Health Board, Penrhosgarnedd, Bangor, Gwynedd, North Wales LL57 2PW, UK; ${ }^{7}$ Department of Gynaecological Oncology, The Ipswich Hospital NHS Trust, Heath Road, Ipswich, Suffolk IP4 5PD, UK; ${ }^{8}$ Trent Cancer Registry, 5 Old Fulwood Road, Sheffield S10 3TG, UK; ${ }^{9}$ Department of Gynaecological Oncology, University College London Hospital NHS Foundation Trust, 2nd Floor North, 250 Euston Road, London NW1 2PG, UK; ${ }^{10}$ Department of Gynaecological Oncology, Glasgow Royal Infirmary, 16 Alexandra Parade, Glasgow G31 2ER, UK; ${ }^{11}$ Department of Gynaecological Oncology, Lancashire Teaching Hospitals NHS Foundation Trust, Royal Preston Hospital, Sharoe Green Lane, North Fulwood, Preston Lancashire PR2 9HT, UK and ${ }^{12}$ Department of Gynaecological Cancer, Barts Cancer Centre, Barts and the London NHS Trust, St Bartholomew's Hospital (Barts), West Smithfield, London EC1A 7BE, UK

Background: There are limited data on surgical outcomes in gynaecological oncology. We report on predictors of complications in a multicentre prospective study.

Methods: Data on surgical procedures and resulting complications were contemporaneously recorded on consented patients in 10 participating UK gynaecological cancer centres. Patients were sent follow-up letters to capture any further complications. Post-operative (Post-op) complications were graded $(I-V)$ in increasing severity using the Clavien-Dindo system. Grade I complications were excluded from the analysis. Univariable and multivariable regression was used to identify predictors of complications using all surgery for intra-operative (Intra-op) and only those with both hospital and patient-reported data for Post-op complications.

Results: Prospective data were available on 2948 major operations undertaken between April 2010 and February 2012 . Median age was 62 years, with 35\% obese and 20.4\% ASA grade $\geqslant 3$. Consultant gynaecological oncologists performed $74.3 \%$ of operations. Intra-op complications were reported in 139 of 2948 and Grade II-V Post-op complications in 379 of 1462 surgeries.

*Correspondence: Professor U Menon; E-mail: u.menon@ucl.ac.uk

${ }^{13}$ These authors contributed equally to this work.

Received 29 July 2014; revised 16 November 2014; accepted 30 November 2014; published online 23 December 2014

(C) 2015 Cancer Research UK. All rights reserved 0007-0920/15 
The predictors of risk were different for Intra-op and Post-op complications. For Intra-op complications, previous abdominal surgery, metabolic/endocrine disorders (excluding diabetes), surgical complexity and final diagnosis were significant in univariable and multivariable regression $(P<0.05)$, with diabetes only in multivariable regression $(P=0.006)$. For Post-op complications, age, comorbidity status, diabetes, surgical approach, duration of surgery, and final diagnosis were significant in both univariable and multivariable regression $(P<0.05)$.

Conclusions: This multicentre prospective audit benchmarks the considerable morbidity associated with gynaecological oncology surgery. There are significant patient and surgical factors that influence this risk.

Treatment outcomes are increasingly used by commissioners and consumers of health care to evaluate the performance of individual clinicians and institutions. This has led to some specialities developing clinician led national databases such as the National Surgical Quality Improvement Programme (NSQIP) in the United States (Khuri, 1998) and the national audits in cardiac surgery in England (Bridgewater, 2010). The hallmark of such initiatives is collection of comparable accurate data by clinical teams across hospitals, which make the calculation of risk-adjusted morbidity and mortality rates for surgical procedures possible. In gynaecological oncology, there is little such data available, with studies on surgical outcomes limited to single centre reports from United Kingdom (Das et al, 2006) and Australia (Kondalsamy Chennakesavan et al, 2009) and a three centre US ovarian cancer study (Aletti et al, 2007b)

In England, the outcome data for gynaecological oncology procedures undertaken in the National Health Service (NHS) are limited to a few procedures such as hysterectomy and includes both benign and malignant disease. Surrogate markers of surgical performance such as duration of hospital admission ('length of stay'), readmission and repeat surgery ('return to theatre') rates collected as part of Hospital Episode Statistics (www.hesonline.nhs.uk) are used. The latter is an administrative national data repository containing details of all admissions, outpatient appointments and accident/ emergency attendances at NHS hospitals in England. It was initially established to evaluate/monitor resource allocation but is now increasingly being used to compare the quality of care provided by NHS hospitals, with summary data accessible to the public on the web (e.g., www.drfosterhealth.co.uk). However, studies comparing HES outcome data with clinician databases have shown that it is prone to error, omissions and inconsistencies (Westaby et al, 2007; Cockbain et al, 2012). One of the reasons for this is that there is little clinical input into data collection with coding officers capturing data from clinical notes, which are not uniformly standardised or structured across hospitals.

To address this lack of high quality outcome data in gynaecological oncology, the United Kingdom Gynaecological Oncology Surgical Outcomes and Complications (UKGOSOC) study was undertaken to contemporaneously capture relevant data from participating gynaecological oncology centres. Here, we report on the type and incidence of intra- and post-operative complications in gynaecological oncology surgery and significant predictors of risk.

\section{STUDY DESIGN AND METHODS}

Certain aspects of the study design have been previously described (Iyer et al, 2013). A web-based custom built database was designed to capture data at various stages during the patient's surgical pathway, hosted on a secure server at the Trent Cancer Registry. The website was accessible only through N3 (N3.nhs.uk), which is a secure private network service used by NHS hospitals in England, Wales and Scotland. Advice was sought from the Joint UCL/UCLH Committees on the Ethics of Human Research in June 2008, which confirmed that the study was similar to an audit and did not require formal ethical review. However, because patients were sent a follow-up letter (FUL) from the co-ordinating centre (CC) at University College London (UCL), informed consent was obtained (Supplementary File). Patients were given the option of providing either identifiable or anonymised data as per their preference.

Data collection. Training in the use of the web-based programme was provided by one of the CC team members either in person or remotely via web conferencing. Each centre user had a unique username and password. Clerical staff entered details of consecutive surgical patients (who had given prior consent) listed on the participating surgeon's list. Clinical staff entered data on surgery, Intra-op complications and the Post-op course (including any complications) contemporaneously online from the theatre and ward respectively. Once entered and saved, data could not be deleted or changed unless the clinical teams contacted the CC.

All major surgical procedures performed on a gynaecological oncology theatre list were included in the study. In addition to surgery for malignancy, the procedures included surgery for benign conditions where there was a high pre-operative suspicion of cancer, cases with a complex surgical history which had been referred to the gynaecological oncology team and risk-reducing surgery. Minor diagnostic procedures and repeat surgery for complications were excluded.

Comorbidity. Pre-operative information on patients included age, comorbidity, American Society of Anaesthesiologists (ASA) grade (1-4) (Soliani, 1963), body mass index (BMI) and details of any previous surgery. Comorbidity (yes/no) was captured under the following categories: cardiac, coagulation/thrombosis, diabetes, gastrointestinal, hypertension, integumentary/dermatology, infections, low albumin $\left(<30 \mathrm{gl}^{-1}\right)$, metabolic/endocrine, neurological, psychiatric, respiratory, smoking, vascular and other neoplasms.

Surgery. Surgical procedures were captured using the relevant Office of the Population Censuses and Surveys (OPCS) Classification of Interventions and Procedures version 4.5 and 4.6 codes. Surgical complexity was classified using a modification of the surgical scoring system (Supplementary Table 1) developed by Aletti et al (2007a) for ovarian cancer. Each individual procedure was given a score and the total score for the surgery was the sum of the individual scores. For example, if adhesiolysis (score 1) and ureterolysis (score 1) were performed along with a total abdominal hysterectomy (TAH, score 1), the surgical complexity score was 3 . Surgeries were categorised into five groups of increasing complexity based on the overall score (surgical complexity score 1 and 2: Group 1; 3 and 4: Group 2; 5 and 6: Group 3; 7 and 8: Group 4; $>8$ : Group 5). In addition to the procedure, the grade of operating surgeon, duration of surgery, the surgical approach (open/ laparoscopic/vulval-vaginal) and estimated blood loss (EBL) were also recorded.

Diagnosis. The diagnosis was recorded using the International Statistical Classification of Diseases and Related Health Problems codes (ICD-10) (WHO, 1990). For the analysis, the final 
histological diagnosis post-surgery was grouped into five categories: (1) ovarian which included primary ovarian/fallopian tube/ peritoneal, non-gynae primary and unknown primary cancers (where the preoperative diagnosis had been suspected to be an ovarian primary); (2) uterine which included primary endometrial cancer, carcinosarcoma and sarcomas of the uterus; (3) cervix (primary cervical cancer); (4) vulva which included primary vulval and vaginal cancers; and (5) benign.

Complications. A surgical complication was defined as 'an undesirable and unintended result of an operation affecting the patient that occurs as a direct result of the operation' (Sokol and Wilson, 2008). Post-op complications were defined as those complications occurring post-operatively up to 8 weeks after surgery. To capture Intra-op and Post-op complications, a pre-determined list of complications was compiled following literature review and several group discussions involving the participating surgeons (Supplementary Table 2). Intra-op complications were recorded by the surgeons in theatre. Estimated blood loss of $>2.51$ was documented as Intra-op haemorrhage, regardless of whether haemorrhage was specifically identified as a complication by the operating surgeon. Completeness of Post-op complications was ensured by including both hospital-reported and patient-reported (via FULs) data as previously detailed (Iyer et al, 2013). Post-op complications were graded I-V using the Clavien and Dindo system based on the severity and intervention required (Dindo et al, 2004) (Supplementary Table 3). Only Grade II-V Post-op complications were included in the analysis. Grade 1 complications were excluded as they were by definition 'any deviation from the normal post-operative course not requiring any pharmacological/surgical/radiological intervention' and therefore likely to be subject to individual variation and to have minimal impact on the post-operative course (Iyer et al, 2013).

Data cleaning. The database was checked on a weekly basis by the clinical research fellow (RI) at the $\mathrm{CC}$ and the centres were contacted for any missing data or for clarification/correction of erroneous data.

Statistical analysis. Statistical analysis was performed using STATA version 12.1 (StataCorp 2012; StataCorp LP, College Station, TX, USA). Descriptive statistics were used to characterise the cohort. Surgery was used as the denominator for all the analyses as there were 38 women who had undergone two separate procedures as part of their treatment (repeat surgeries for complications were excluded). In addition, it was possible that age, comorbidity and ASA grade could change over time in an individual woman. All eligible surgeries were included to calculate the crude or unadjusted Intra-op complication rate (CR) and for the Post-op CR analysis was limited to those with both hospitaland patient-reported data. To assess how each potential predictor affected the CR individually, univariable logistic regressions were performed separately for all predictors. For Intra-op complications, the independent variables included age, the presence of comorbidities (yes/no), type of comorbidities, BMI (continuous variable and categorical-underweight, normal, overweight, obese and morbidly obese), ASA grade (1-4), previous abdominal surgery (yes/no), grade of operating surgeon (consultant, sub-specialty trainee, general obstetrics and gynaecology trainee), surgical approach (laparotomy/laparoscopy), surgical complexity (1-5) and final diagnosis (ovarian, uterine, cervix, vulva and benign). For Post-op complications, two additional variables-duration of surgery (in hours) and EBL (<500 mls, $500-1000 \mathrm{mls},>1000-2500 \mathrm{mls}$, $>2500 \mathrm{mls}$ ) were included.

To create a risk prediction model for both the Intra-op and Post-op CRs, useful predictors were identified in a multivariable logistic regression model by running a stepwise regression with backward elimination, with $P($ removal $)=0.05$. Significant categorical predictors with more than two categories were retained complete rather than dropping any insignificant categories. Goodness of fit was assessed using the Hosmer-Lemeshow test (with the data split into 10 groups based on estimated probabilities). Since 38 women had repeated outcomes, the data should formally be considered longitudinal (with very short panels). Another possible source of correlated errors was through clustering at each hospital. Hence, cluster robust standard errors were used and additionally, a random effects logistic regression model was fitted using the identified predictors to test the null hypothesis that the possible clustering factors were not significant.

\section{RESULTS}

During the prospective UKGOSOC audit, undertaken between 1st April 2010 and 29th February 2012, 10 centres submitted a total of 3026 operations. In all, 78 operations were excluded as they were minor diagnostic procedures (54) and surgeries for complications (24). The remaining 2948 operations involving 2910 women (38 had two surgeries each) were included in the analysis. Patientreported complications were available for 1462 (68\%) of the surgeries and the CONSORT diagram for the latter has been detailed previously (Iyer et al, 2013).

Patients. The baseline characteristics of the women are detailed in Table 1 and the overall surgery details are described in Table 2. Overall, 33.5\% (989) of the surgeries were for ovarian, $27.8 \%$ (820) for uterine, $7 \%$ (207) for cervical, 6\% (176) for vulval cancer and $25.6 \%$ (756) for benign pathologies.

Surgery for individual diagnostic categories. For ovarian cancers, $93.4 \%$ (924 out of 989) of the operations were open procedures and $6.6 \%$ (65 out of 989) were laparoscopic. In all, $8.2 \%$ (81) of the procedures required a bowel resection and $5.8 \%$ (57) required upper abdominal debulking involving the diaphragm, spleen, liver, etc.

For uterine cancers, $90 \%$ (738 out of 820 ) of the procedures were total hysterectomies ( \pm lymphadenectomy) of which $58.4 \%$ (431 out of 738) were open procedures in which lymphadenectomy had been performed in $38.5 \%$ (166 out of 431 ). In all, $41.6 \%$ (307 out of 738) of the hysterectomies were performed via the laparoscopic approach in which lymphadenectomy was performed in $26.8 \%$ ( 82 out of 307 ). The median BMI of women undergoing the open $v$ s laparoscopic hysterectomy was similar (30.1; IQR 25.735.3 vs 31.3; IQR 26.1-36.2, respectively).

For cervical cancers, $26.6 \%$ (55 out of 207) of the procedures were open radical hysterectomies in which lymphadenectomy had been performed in $76.6 \%$ (42). In all, $24.2 \%$ (50 out of 207 ) were laparoscopic radical hysterectomies which included lymphadenectomy in 94\% (47). The median BMI for the two approaches was similar, 26.3 (IQR 23.2-31.6) for open and 25 for laparoscopic (IQR 22.4-30.7).

For vulval cancer, vulvectomy was the commonest procedure (95 out of 176,54\%), followed by vulvectomy with inguinofemoral lymphadenectomy (46 out of 176, 26.1\%).

For benign pathology, total abdominal hysterectomy (TAH) with bilateral salpingo-oophorectomy (BSO) + omentectomy/lymphadenectomy/appendicectomy ( 318 out of $756,42.1 \%$ ) was the commonest procedure followed by simple TAH with BSO (178 out of 756, 23.5\%).

Intra-operative complications. In total, 139 of 2948 surgeries had an Intra-op complication giving an overall Intra-op CR of $4.7 \%$ (95\% CI 4.0-5.6). This included 143 individual Intra-op complications (i.e., four surgeries had two complications each) (Table 3). Intra-op haemorrhage (28.7\%; 41 out of 143 ) followed by bladder $(15.4 \%$; 22 out of 143$)$ and small bowel $(15.4 \%$; 22 out of 143$)$ 
Table 1. Baseline characteristics

Baseline characteristics $(n=2948)$

\begin{tabular}{|l|l|}
\hline Age (in years, median, IQR) & $62(50-71)$ \\
\hline
\end{tabular}

\section{BMI}

\begin{tabular}{|l}
\hline BMI (median, IQR) \\
\hline BMI category \\
\hline Underweight $(<18.5)$ \\
Normal $(18.5-24.9)$ \\
Overweight $(25-29.9)$ \\
Obese $(30-39.9)$ \\
Morbidly obese $(\geqslant 40)$ \\
Missing
\end{tabular}

$27.4(23.8-32.4)$

\section{ASA grade}

\begin{tabular}{|l|r|}
\hline 1 and 2 & $2341(79.4)$ \\
$\geqslant 3$ & $600(20.4)$ \\
Missing & $7(0.2)$
\end{tabular}

\begin{tabular}{|l|r|}
\hline Comorbidity & \\
\hline 0 & $1105(37.5)$ \\
$1-3$ & $1716(58.2)$ \\
$>3$ & $127(4.3 \%)$ \\
\hline
\end{tabular}

\section{Type of comorbidity}

\begin{tabular}{|l|l}
\hline Hypertension & $973(33)$
\end{tabular}

\begin{tabular}{l|l} 
Cardiac & $308(10)$
\end{tabular}

Diabetes

Respiratory

Musculoskeletal

Neurology/psychiatric

Other neoplasms

Coagulation/thrombosis

Gastrointestinal

Smoking

Vascular

Genitourinary

Autoimmune

Integumentary/Dermatology

Infections

Low albumin

$298(10)$

287 (10)

261 (9)

$208(7)$

$148(5)$

$116(4)$

$104(4)$

95 (3)

86 (3)

$52(2)$

37 (1)

$30(1)$

$13(0.4)$

$11(0.4)$

Previous abdominal surgery

1025 (34.7)

Abbreviations: $\mathrm{ASA}=$ American Society of Anaesthesiologists; $\mathrm{BMI}=$ body mass index; $\mathrm{IQR}=$ interquartile range.

injury were the most frequently occurring Intra-op complications. In the 2192 operations with a cancer diagnosis, 118 had an Intraop complication resulting in an Intra-op CR for cancer surgery of 5.4\% (95\% CI 4.5-6.4) and this included 121 individual Intra-op complications.

The highest Intra-op CR was for ovarian cancer surgery (78 out of $989 ; 7.9 \%, 95 \%$ CI $6.4-9.7)$. Two out of the three exenterations had an Intra-op complication (66.8\%). The Intra-op CR was $19.8 \%$ (16 out of 81 ) for procedures with bowel resection and $14 \%$ (8 out of 57) for procedures involving upper abdominal surgery.

Cervical cancer surgery had the second highest Intra-op CR (10 out of 207, 4.8\%; 95\% CI 2.6-8.7). The Intra-op CR for the subset of open radical hysterectomies was 5.5\% (3 out of 55) and was almost double $(10 \%, 5$ out of 50) for laparoscopic radical hysterectomies. Emergency laparotomy was required for only one $(2 \% ; 1$ out of 50$)$ of the laparoscopic radical hysterectomies.

For uterine cancer surgery, the overall Intra-op CR was 3.4\% (28 out of $820,95 \%$ CI 2.4-4.9). Where hysterectomy was undertaken, the Intra-op CR was $2.6 \%$ (11 out of 431 ) for the open approach and $3.6 \%$ (11 out of 307) for the laparoscopic approach. The Intraop CR for the subgroup of hysterectomies with lymphadenectomy was $1.8 \%$ ( 3 out of 166 ) for open and $7.3 \%$ (6 out of 82 ) for laparoscopic surgery. The unscheduled laparotomy rate for the laparoscopic approach was $1.6 \%$ (5 out of 307 ).

Intra-op haemorrhage was the most common complication for ovarian, uterine and cervical cancer surgery (Table 3 ).

\section{Table 2. Surgery details}

Grade of operating surgeon

n (\%)

Consultant

Sub-specialty trainee

General Obstetrics and Gynaecology Trainee

2191 (74.3)

573 (19.4)

$108(3.7)$

Missing

$76(2.6)$

Diagnosis

n $(\%)$

Ovarian $^{\text {a }}$

Uterine $^{b}$

989 (33.5)

Cervical

$820(27.8)$

Vulval $^{c}$

207 (7.0)

Benign

$176(6.0)$

$756(25.7)$

\section{Surgical approach}

n $(\%)$

\section{Open}

Laparoscopic elective proceed to laparotomy

2001 (67.9)

Laparoscopic emergency proceed to laparotomy

$68(2.3)$

Laparoscopic $^{\mathbf{d}}$

Vulval/vaginal procedures

$11(0.3)$

$670(22.7)$

$198(6.7)$

\section{Duration of surgery (minutes)}

Median, IQR

Open procedures

Laparoscopic procedures

Vulval/vaginal procedures

$120(90-167)$

120 (85-170)

87 (50-148)

\section{Surgical complexity}

$n(\%)$

Group 1 (complexity score 1 and 2)

Group 2 (complexity score 3 and 4)

Group 3 (Complexity score 5 and 6)

Group 4 (complexity score 7 and 8)

Group 5 (complexity score >8)

1398 (47)

982 (33)

430 (15)

93 (3)

45 (2)

\section{Surgical procedures}

n (\%)

$\mathrm{TAH} \pm \mathrm{BSO}+$ omentectomy /appendicectomy/

lymphadenectomy/peritonectomy

$\mathrm{TAH} \pm \mathrm{BSO} / \mathrm{USO}$

Radical hysterectomy $\pm \mathrm{BSO} \pm$ lymphadenectomy

TAH/BSO/omentectomy + bowel resection

$\mathrm{TAH}+\mathrm{BSO}+$ omentectomy + upper abdominal

n (\%)

\section{surgery}

Exenterations \pm conduits

Open lymphadenectomy

Exploratory/abandoned procedure

Other open procedures

TLH/LAVH + BSO

TLH or LAVH \pm omental biopsy + lymphadenectomy

Laparoscopic radical hysterectomy

\pm lymphadenectomy

Laparoscopic lymphadenectomy

Other laparoscopic procedures

Vulvectomy (radical/simple)

Vulvectomy + Inguinofemoral lymphadenectomy

Inguinofemoral lymphadenectomy

Vaginectomy

$1202(40.8)$

Other vulval/vaginal procedures

448 (15.2)

106 (3.6)

94 (3.2)

$58(2.0)$

$16(0.5)$

$14(0.5)$

$29(1.0)$

105 (3.6)

306 (10.4)

262 (8.9)

65 (2.2)

\section{Length of stay}

$30(1.0)$

$18(0.6)$

$113(3.8)$

$46(1.6)$

$18(0.6)$

$12(0.4)$

$6(0.2)$

\begin{tabular}{|c|c|}
\hline & (IQR) \\
\hline Open procedures & $4(3-6)$ \\
\hline Laparoscopic & $2(1-2)$ \\
\hline Vulval/vaginal procedures & $4(2-7)$ \\
\hline \multicolumn{2}{|c|}{$\begin{array}{l}\text { Abbreviations: } \mathrm{BSO}=\text { bilateral salpingo-oophorectomy; } \mathrm{LAVH}=\text { laparoscopic assisted } \\
\text { vaginal hysterectomy; } \mathrm{TAH}=\text { total abdominal hysterectomy; } \mathrm{TLH}=\text { total laparoscopic } \\
\text { hysterectomy; } \mathrm{USO}=\text { unilateral salpingo-oophorectomy. } \\
\mathrm{a}_{\text {Includes primary ovarian, fallopian tube, primary peritoneal, synchronous, non-gynae }} \\
\text { primary cancers. } \\
\mathrm{b}_{\text {Includes primary endometrial cancer, carcinosarcoma and sarcoma of the uterus. }} \\
\mathrm{c}_{\text {Includes primary vulval and vaginal cancers. }} \\
\mathrm{d}_{\text {Includes total laparoscopic and laparoscopic assisted vaginal procedures. }}\end{array}$} \\
\hline
\end{tabular}




\begin{tabular}{|c|c|c|c|c|c|c|}
\hline \multicolumn{7}{|c|}{ Intra-operative complications (no. of surgery $=2948$ ) } \\
\hline \multirow[b]{2}{*}{ Complication category } & \multirow[b]{2}{*}{ Total no. (\% with complication) } & \multicolumn{4}{|c|}{ Primary cancer site } & \multirow[b]{2}{*}{ Benign } \\
\hline & & Ovary $^{a}$ & Uterine $^{\mathrm{b}}$ & Cervix & Vulva ${ }^{c}$ & \\
\hline Intra-operative haemorrhage & $41(28.7)$ & 27 & 8 & 3 & & 3 \\
\hline Bladder injury & $22(15.4)$ & 11 & 3 & 2 & 2 & 4 \\
\hline GI tract injury—small bowel & $22(15.4)$ & 16 & 4 & & & 2 \\
\hline GI tract injury_large bowel & $11(7.7)$ & 4 & 2 & 1 & & 4 \\
\hline Vascular injury & $13(9.1)$ & 7 & 2 & 1 & & 3 \\
\hline Vaginal tear & $7(4.9)$ & & 5 & & & 2 \\
\hline Cardiac & $6(4.2)$ & 2 & & 1 & & 3 \\
\hline Diaphragmatic injury & $5(3.5)$ & 5 & & & & \\
\hline Ureteric injury & $5(3.5)$ & 1 & 2 & 1 & & 1 \\
\hline Splenic injury & $3(2.1)$ & 3 & & & & \\
\hline Gall bladder injury & $1(0.7)$ & & 1 & & & \\
\hline Liver laceration & $1(0.7)$ & 1 & & & & \\
\hline Nerve injury & $1(0.7$ & & & 1 & & \\
\hline Respiratory & $1(0.7)$ & 1 & & & & \\
\hline Uterine perforation & $1(0.7)$ & & 1 & & & \\
\hline Anaphylaxis & $1(0.7)$ & & 1 & & & \\
\hline Other & $2(1.4)$ & 1 & 1 & & & \\
\hline Total no. of intra-op complications (\% of total surgery) & $143(4.9 \%)$ & 79 (7.9\%) & $30(3.4 \%)$ & $10(4.8 \%)$ & $2(1.1 \%)$ & $22(2.8 \%)$ \\
\hline Total no. of surgeries & 2948 & 989 & 820 & 207 & 176 & 756 \\
\hline \multicolumn{7}{|c|}{ 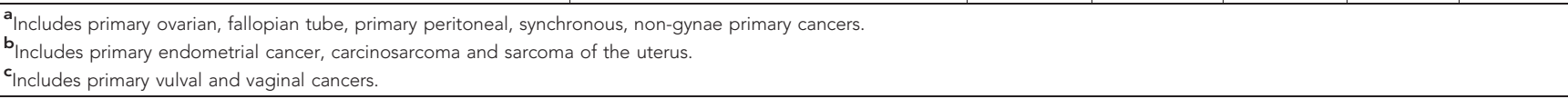 } \\
\hline
\end{tabular}

There were only two surgeries with an Intra-op complication for vulval cancer (2 out of 176, 1.1\%; 95\% CI 3.1-4.1) and both were bladder injuries. The Intra-op CR (21 out of 756, 2.8\%; 95\% CI 1.84.2) was lower for benign conditions when compared with ovarian, uterine and cervix cancer surgery. Bladder and large bowel injuries were the most commonly occurring complications (4 out of $756,0.5 \%$ ).

The Intra-op CR increased with increasing surgical complexity with rates of $2.9 \%$ (41 out of 1398) for a surgical score of $<3,4.4 \%$ (43 out of 982) for a score of $3-4,7.9 \%$ (34 out of 430) for a score of $5-6,12.9 \%$ (12 out of 93) for a score of $7-8$ and $20 \%$ (9 out of 45 ) for a score of $>8$. Overall, the highest Intra-op CR was seen for procedures with bowel resection (18 out of 94, 19.1\%) and exenterations ( 3 out of $16,18.8 \%$ ) followed by debulking surgery requiring upper abdominal resection (8 out of $58,13.8 \%$ ).

Post-operative complications. Both hospital and patient reported data on Post-op complications were available for 1462 surgeries. There were 200 hospital-reported and 252 patient-reported Grade II-V complications in 379 surgeries resulting in an overall Post-op CR of $25.9 \%$ (95\% CI 23.7-28.2) as previously reported (Iyer et al, 2013). Out of the total 452 Grade II-V complications, wound (140 out of $452,30.9 \%$ ) and other infections (126 out of 452, 27.8\%) were the most common (Table 4). In the 1067 operations leading to a cancer diagnosis, 289 had a Post-op complication resulting in a Postop CR for cancer surgery of $27.1 \%$ (95\% CI 24.5-29.8).

Surgery for vulval cancer had the highest Post-op CR (33 out of 79, $41.8 \% 95 \%$ CI 31.5-52.8). Wound breakdown/infection (26 out of 79, $32.9 \%)$ was the most common complication. In over one in three procedures with inguinofemoral lymphadenectomy, the main complication was lymphocysts/lymphoedema (15 out of 42, 35.7\%).

Cervical cancer surgery had a similar Post-op CR (32 out of 80, 40\%; 95\% CI 29.9-50.9) to vulval cancer surgery with similar rates for open (11 out of $27,40.7 \%$ ) vs laparoscopic radical hysterectomy \pm lymphadenectomy (8 out of $20,40 \%$ ). Infections (excluding wound) were the most common complication (7 out of $80,8.8 \%$ ). When compared with vulval cancer surgery, the incidence of lymphocysts/lymphoedema was lower at $12.7 \%$ (7 out of 55 procedures with lymphadenectomy).

Ovarian cancer surgery had a significantly lower Post-op CR (128 out of $481,26.6 \%$, 95\% CI 22.9-30.7) when compared with vulval and cervical cancer surgery. Exenterations (one out of two; $50 \%$ ), procedures including upper abdominal surgery (11 out of $26,42.3 \%)$ and bowel resection (11 out of $35,31.4 \%)$ had the highest rates. Infections (excluding wound) remained the most common $(8.5 \%$; 41 out of 481$)$ complication.

The Post-op CR for uterine cancer surgery was 22.5\% (96 out of 427, 22.5\%; 95\% CI 18.8-26.7). The Post-op CR for hysterectomies \pm lymphadenectomy was $26.8 \%$ (63 out of 235 ) for the open and $16.2 \%$ (25 out of 154) for the laparoscopic approach. For the subset of hysterectomies with lymphadenectomy, the Post-op CR was 37.9\% (36 out of 95) for the open and $19.6 \%$ (10 out of 51) for the laparoscopic approach. The incidence of lymphocysts/lymphoedema was $7.1 \%$ (11 out of 156) for procedures with lymphadenectomy, a lower rate than that for cervical and vulval cancers.

For benign pathology, the Post-op CR was $22.8 \%$ (90 out of 395 ; 95\% CI 18.9-27.2). TAH with BSO had the highest Post-op CR (29 out of 96, 30.2\%) followed by Total Laparoscopic Hysterectomy $( \pm \mathrm{BSO})(10$ out of $38,26.3 \%)$. Wound breakdown (38 out of 395 , $9.6 \%$ ) and infections (excluding wound) (33 out of $395,8.4 \%$ ) were the most common type of complications (Table 4).

Grade of complications. In total, 402 (88.9\%) out of the 452 complications in this cohort of 1462 surgeries were Grade II and 50 (11.1\%) were Grade III or worse (8 Grade IIIa, 30 Grade IIIb, 10 Grade IVa and 2 Grade V) (Supplementary Table 4). 
Table 4. Hospital and patient-reported post-operative complications

\begin{tabular}{|c|c|c|c|c|c|c|}
\hline \multicolumn{7}{|c|}{ Grade II-V hospital- and patient-reported post-operative complications (no. of surgery $=1462$ ) } \\
\hline \multirow[b]{2}{*}{ Complication category } & \multirow[b]{2}{*}{ Total no. (\% with complication) } & \multicolumn{4}{|c|}{ Primary cancer site } & \multirow[b]{2}{*}{ Benigr } \\
\hline & & Ovary $^{a}$ & Uterine $^{b}$ & Cervix & Vulva $^{c}$ & \\
\hline Wound breakdown & $140(30.1)$ & 37 & 35 & 4 & 26 & 38 \\
\hline Infection & $126(27.8)$ & 41 & 30 & 17 & 5 & 33 \\
\hline Lymphocyst/lymphoedema & $39(8.6)$ & 6 & 11 & 7 & 15 & \\
\hline Bladder & $17(3.8)$ & 2 & 7 & 2 & & 6 \\
\hline Abscess/haematoma & $14(3.1)$ & 6 & 2 & 2 & & 4 \\
\hline Ileus & $16(3.5)$ & 11 & 3 & & & 2 \\
\hline Bowel obstruction & $7(1.5)$ & 5 & 1 & & & 1 \\
\hline Bowel perforation & $2(0.4)$ & 1 & 1 & & & \\
\hline Bowel-other & $11(2.4)$ & 5 & 1 & 1 & & 4 \\
\hline Primary haemorrhage & $5(1.1)$ & 2 & 2 & & & 1 \\
\hline Secondary haemorrhage & $10(2.2)$ & 2 & 3 & 1 & & 4 \\
\hline Fistula & $7(1.5)$ & 4 & 1 & 1 & & 1 \\
\hline Anastomotic leak & $2(0.4)$ & 2 & & & & \\
\hline Cardiac & $7(1.5)$ & 4 & 2 & & & 1 \\
\hline Pulmonary embolism & $5(1.1)$ & 3 & 2 & & & \\
\hline Deep vein thrombosis & $5(1.1)$ & 2 & 1 & 1 & & 1 \\
\hline Respiratory & $6(1.3)$ & 3 & 2 & & & 1 \\
\hline Neurological & $4(0.9)$ & & 1 & & & 3 \\
\hline Psychiatric & $2(0.4)$ & 1 & & & & 1 \\
\hline Hernia & $4(0.9)$ & 3 & 1 & & & \\
\hline Ureteric obstruction & $1(0.2)$ & & 1 & & & \\
\hline Other & $22(4.9)$ & 8 & 5 & 2 & 1 & 6 \\
\hline $\begin{array}{l}\text { Total no. of post-operative complications } \\
\text { (\% of total surgery) }\end{array}$ & $\begin{array}{c}452 \\
(30.9)\end{array}$ & $\begin{array}{c}148 \\
(30.7)\end{array}$ & $\begin{array}{c}112 \\
(26.2)\end{array}$ & $\begin{array}{c}38 \\
(47.5)\end{array}$ & $\begin{array}{c}47 \\
(59.5)\end{array}$ & $\begin{array}{c}107 \\
(27.1)\end{array}$ \\
\hline Total no. of surgeries & 1462 & 481 & 427 & 80 & 79 & 395 \\
\hline
\end{tabular}

There were 48 re-admissions (48 out of 1462, 3.6\%), 34 returns to theatre (30 Grade IIIb and 4 Grade IVa; $2.3 \%)$ and $10(2.2 \%)$ unscheduled admissions to intensive care. There were two $(0.14 \%)$ peri-operative deaths reported in this cohort, one due to cardiac failure and the other secondary to bowel perforation.

\section{Predictors of complications}

Intra-op CR. In univariable analysis, the significant predictors of Intra-op complications were previous abdominal surgery, metabolic/endocrine conditions excluding diabetes (patient factors), surgical complexity and final diagnosis (Table 5, Supplementary Table 5). In multivariable regression, all four factors continued to be significant with previous abdominal surgery $(\mathrm{OR}=1.6)$, increasing surgical complexity $(P<0.0005)$ and ovarian cancer diagnosis $(P<0.0005)$ increasing risk along with diabetes $(\mathrm{OR}=2)$ and the presence of metabolic/endocrine disorders (excluding diabetes) $(\mathrm{OR}=0.35)$ associated with decreased risk of Intra-op complication (Table 5).

Post-op-CR. In univariable regression, the significant patient factors associated with increased risk of Post-op complications were diabetes, the presence of any comorbidity, previous abdominal surgery and increasing ASA grade, age and BMI (Table 6, Supplementary Table 6). Among the Intra-op factors, surgical complexity, surgery duration and EBL increased risk whereas laparoscopic compared with open approach reduced the likelihood of a Post-op complication. As with Intraop complications, final diagnosis was a significant predictor. In multivariate regression, the only patient factors that increased risk were the presence of comorbidity $(\mathrm{OR}=1.3)$ and diabetes $(\mathrm{OR}=1.6)$. Significant Intra-op variables were laparoscopic approach that was associated with decreased risk of Post-op complications $(\mathrm{OR}=0.65)$ and duration of surgery in hours that increased risk $(\mathrm{OR}=1.3)$. Unlike for Intra-op complications, increased risk was associated with a diagnosis of vulval/vaginal $(\mathrm{OR}=2.4)$ and cervical cancer $(\mathrm{OR}=1.7)$.

\section{DISCUSSION}

This prospective multicentre UK study is the largest published study that we are aware of which reports on the morbidity associated with surgery undertaken in gynaecological oncology centres. Whilst the overall Intra-op CR was $4.7 \%$, it was $5.4 \%$ when limited to confirmed malignancies. Previous abdominal surgery, diabetes, surgical complexity and final diagnosis were significant predictors of increased risk. The Post-op CR was similar for overall (26\%) and for confirmed malignancies $(27 \%)$. The only common predictors of both Intra-op and Post-op complications were diabetes and final diagnosis. Other significant associations with Post-op complications were age, the presence of comorbidity, 
Table 5. Significant predictors of intra-operative complications in univariable and multivariable regression

\begin{tabular}{|c|c|c|c|c|}
\hline Variable & Odds ratio & $95 \%$ Confidence interval & Standard error & $P$-value \\
\hline \multicolumn{5}{|c|}{ Univariable analysis of risk factors for intra-operative complications as the outcome } \\
\hline Previous abdominal surgery & 1.74 & $1.239-2.455$ & 0.304 & 0.001 \\
\hline Metabolic/endocrine (excluding diabetes) & 0.383 & $0.168-0.876$ & 0.162 & 0.023 \\
\hline \multicolumn{5}{|l|}{ Surgical complexity group } \\
\hline $\begin{array}{l}1 \\
2 \\
3 \\
4 \\
5 \\
\text { Joint significance for all the categories in surgical complexity }\end{array}$ & $\begin{array}{l}1 \\
1.516 \\
2.841 \\
4.903 \\
8.274\end{array}$ & $\begin{array}{c}0.980-2.344 \\
1.779-4.539 \\
2.481-9.690 \\
3.741-18.301\end{array}$ & $\begin{array}{l}0.337 \\
0.679 \\
1.704 \\
3.351\end{array}$ & $\begin{array}{l}0.061 \\
0.000 \\
0.000 \\
0.000 \\
0.000 \\
\end{array}$ \\
\hline \multicolumn{5}{|l|}{ Final diagnosis } \\
\hline $\begin{array}{l}\text { Ovary } \\
\text { Uterine } \\
\text { Benign } \\
\text { Vulva } \\
\text { Cervix } \\
\text { Joint significance for all the categories in final diagnosis }\end{array}$ & $\begin{array}{l}1 \\
0.413 \\
0.334 \\
0.134 \\
0.593\end{array}$ & $\begin{array}{l}0.265-0.643 \\
0.204-0.546 \\
0.033-0.551 \\
0.302-1.166\end{array}$ & $\begin{array}{l}0.093 \\
0.084 \\
0.097 \\
0.205\end{array}$ & $\begin{array}{l}0.000 \\
0.000 \\
0.005 \\
0.130 \\
0.000\end{array}$ \\
\hline \multicolumn{5}{|c|}{ Multivariable logistic regression model for intra-operative complication as the outcome } \\
\hline $\begin{array}{l}\text { Diabetes } \\
\text { Metabolic/endocrine disorders (excluding diabetes) } \\
\text { Previous abdominal surgery }\end{array}$ & $\begin{array}{l}2.015 \\
0.351 \\
1.561\end{array}$ & $\begin{array}{l}1.223-3.324 \\
0.152-0.809 \\
1.099-2.219\end{array}$ & $\begin{array}{l}0.514 \\
0.150 \\
0.280\end{array}$ & $\begin{array}{l}0.006 \\
0.014 \\
0.013\end{array}$ \\
\hline \multicolumn{5}{|l|}{ Surgical complexity group } \\
\hline $\begin{array}{l}1 \\
2 \\
3 \\
4 \\
5\end{array}$ & $\begin{array}{l}1 \\
1.302 \\
2.311 \\
3.397 \\
5.399 \\
\end{array}$ & $\begin{array}{l}0.834-2.033 \\
1.396-3.826 \\
1.660-6.951 \\
2.335-12.48\end{array}$ & $\begin{array}{l}0.296 \\
0.594 \\
1.241 \\
2.309 \\
\end{array}$ & $\begin{array}{l}0.246 \\
0.001 \\
0.001 \\
0.000\end{array}$ \\
\hline \multicolumn{5}{|l|}{ Final diagnosis } \\
\hline $\begin{array}{l}\text { Ovary } \\
\text { Uterine } \\
\text { Cervix } \\
\text { Vulva } \\
\text { Benign }\end{array}$ & $\begin{array}{l}1 \\
0.555 \\
0.599 \\
0.193 \\
0.468 \\
\end{array}$ & $\begin{array}{l}0.348-0.887 \\
0.296-1.212 \\
0.046-0.805 \\
0.278-0.787\end{array}$ & $\begin{array}{l}0.133 \\
0.215 \\
0.141 \\
0.124\end{array}$ & $\begin{array}{l}0.014 \\
0.154 \\
0.024 \\
0.004\end{array}$ \\
\hline
\end{tabular}

surgical approach and duration of surgery. Gynaecological oncology surgery is associated with considerable morbidity and our study provides much needed estimates of complication risk associated with procedures for specific cancers to counsel patients and benchmark surgical performance.

Strengths of UKGOSOC include prospective data collection using standard forms, large sample size and multicentre design with 10 participating gynaecological cancer centres. Data capture from both clinicians and patients ensured completeness of Post-op complications. An online database, accessible to the clinical team whether they were in theatre, wards or outpatient departments facilitated capture of surgical data and complication events contemporaneously. Validity of the data was ensured by weekly review by an independent clinician at the $\mathrm{CC}$, who contacted the teams on a regular basis to retrieve missing data and 'clean' erroneous entries. While clinician-led databases collect more accurate and complete information compared with administrative databases like HES (RCOG, 2012), this was a very resource intensive process. The heavy reliance of UKGOSOC on the clinical teams was a limitation. Most centres, especially those relying on junior trainees on four to six monthly rotations, struggled with prospective data entry.

As this was a prospective study rather than an audit, patient consent was required. In keeping with majority of clinical studies, we are unable to provide an accurate number of women who were approached. Therefore, it is likely that all consecutive patients on operating lists have not been included. In $10 \%$ of surgeries, patients had Metabolic/Endocrine disorders other than diabetes. This mainly included hypercholesterolaemia and thyroid dysfunction and was a predictor of reduced intra-operative CR. We are unable to explain this and as previous studies have not looked at this separately, there is no data for comparison. Some pre-operative biochemical markers such as serum albumin and liver enzymes that have been reported to be predictors of surgical complications (Khuri, 1998; Copeland, 2002; Aletti et al, 2007b; Kondalsamy Chennakesavan et al, 2009) could not be included in our study as they are not routinely assayed in all patient undergoing gynaecological oncology surgery in United Kingdom.

Our overall Intra-op CR of $4.7 \%$ was lower than the $8 \%$ reported from a tertiary gynaecological oncology centre in Australia (Kondalsamy Chennakesavan et al, 2009), which we feel was probably influenced by the small sample size of 381 women in their study compared with nearly 3000 in ours (Kondalsamy Chennakesavan et al, 2009). No other comparable figures were available in the published literature. Rates for gynaecological malignancy alone were lower than Intra-op CRs in women undergoing pelvic surgery for rectal cancer surgery (12\%) (van der Pas et al, 2013). The lower incidence of Intra-op complications was paralleled by the lower (1.6\%) laparoscopic to emergency laparotomy conversion rates compared with the Australian study $(2.4 \%)$ and the rectal cancer surgery multicentre trial (16\%) (van der Pas et al, 2013). Lower CRs in surgeries for gynaecological compared with colorectal cancer are likely to be related to the lower rates of bowel resection and possible 
Table 6. Significant predictors of post-operative complications in univariable and multivariable regression

\begin{tabular}{|c|c|c|c|c|}
\hline Variable & Odds ratio & $95 \%$ Confidence interval & Standard error & $P$-value \\
\hline \multicolumn{5}{|c|}{ Univariable analysis for post-operative complications as the outcome } \\
\hline Age & 1.014 & $1.002-1.026$ & 0.006 & 0.027 \\
\hline Comorbidity status (yes/no) & 1.477 & $1.049-2.077$ & 0.257 & 0.025 \\
\hline Diabetes & 1.916 & $1.233-2.977$ & 0.431 & 0.004 \\
\hline Previous abdominal surgery & 1.465 & $1.068-2.011$ & 0.237 & 0.018 \\
\hline Body mass index (continuous variable) & 1.023 & $1.001-1.045$ & 0.011 & 0.039 \\
\hline \multicolumn{5}{|l|}{ Body mass index (categorical variable) } \\
\hline Underweight $(<19.9)$ & 1 & & & \\
\hline Normal (19.9-24.9) & 0.709 & $0.156-3.231$ & 0.549 & 0.657 \\
\hline Overweight (25-29.9) & 0.888 & $0.196-4.017$ & 0.684 & 0.877 \\
\hline Obese $(30-39.9)$ & 1.359 & $0.302-6.120$ & 1.044 & 0.689 \\
\hline Morbidly obese (>40) & 0.948 & $0.193-4.652$ & 0.769 & 0.947 \\
\hline Joint significance for all the categories in BMI & & & & 0.037 \\
\hline \multicolumn{5}{|l|}{ ASA grade (1-3) } \\
\hline ASA grade 1 & 1 & & & \\
\hline ASA grade 2 & 1.623 & $1.0422-2.527$ & 0.367 & 0.032 \\
\hline ASA grade $\geqslant 3$ & 2.178 & $1.315-3.608$ & 0.561 & 0.002 \\
\hline Joint significance for all the categories in ASA grade & & & & 0.008 \\
\hline Duration of surgery & 1.496 & $1.324-1.690$ & 0.093 & 0.000 \\
\hline \multicolumn{5}{|l|}{ Approach for surgery } \\
\hline Open & 1 & & & \\
\hline Laparoscopic & 0.506 & $0.326-0.787$ & 0.114 & 0.002 \\
\hline \multicolumn{5}{|l|}{ Surgical complexity group } \\
\hline 1 & 1 & & & \\
\hline 2 & 1.719 & $1.196-2.469$ & 0.318 & 0.003 \\
\hline 3 & 1.896 & $1.198-3.003$ & 0.445 & 0.006 \\
\hline 4 & 2.652 & $1.218-5.774$ & 1.053 & 0.014 \\
\hline 5 & 6.562 & $2.454-17.543$ & 3.292 & 0.000 \\
\hline Joint significance for all the categories in surgical complexity & & & & 0.000 \\
\hline \multicolumn{5}{|l|}{ Estimated blood loss (EBL) } \\
\hline$<500 \mathrm{mls}$ & 1 & & & \\
\hline $500-1000 \mathrm{mls}$ & 2.554 & $1.737-3.756$ & 0.502 & 0.000 \\
\hline$>1000-2500 \mathrm{mls}$ & 2.443 & $1.381-4.319$ & 0.710 & 0.002 \\
\hline$>2500 \mathrm{mls}$ & 0.797 & $0.102-6.226$ & 0.710 & 0.829 \\
\hline Joint significance for all the categories in EBL & & & & 0.000 \\
\hline \multicolumn{5}{|l|}{ Final diagnosis } \\
\hline Ovary & 1 & & & \\
\hline Uterine & 0.609 & $0.407-0.914$ & 0.126 & 0.016 \\
\hline Cervix & 1.623 & $0.908-2.901$ & 0.481 & 0.102 \\
\hline Vulva & 2.024 & $1.158-3.535$ & 0.576 & 0.013 \\
\hline Benign & 0.41 & $0.258-0.652$ & 0.097 & 0.000 \\
\hline Joint significance for all the categories in final diagnosis & & & & 0.000 \\
\hline \multicolumn{5}{|c|}{ Multivariable logistic regression model for post-operative complication as the outcome } \\
\hline Comorbidity status (Yes/No) & 1.338 & $1.012-1.769$ & 0.191 & 0.041 \\
\hline Diabetes & 1.642 & $1.113-2.421$ & 0.325 & 0.012 \\
\hline Age & 0.989 & $0.979-1.000$ & 0.005 & 0.052 \\
\hline Laparoscopic approach & 0.653 & $0.469-0.909$ & 0.110 & 0.012 \\
\hline Duration of surgery & 1.285 & $1.149-1.439$ & 0.074 & 0.000 \\
\hline \multicolumn{5}{|l|}{ Final diagnosis } \\
\hline Ovary & 1 & & & \\
\hline Uterine & 0.998 & $0.716-1.392$ & 0.169 & 0.992 \\
\hline Cervix & 1.664 & $0.958-2.891$ & 0.469 & 0.071 \\
\hline Vulva & 2.398 & $1.438-3.999$ & 0.626 & 0.001 \\
\hline Benign & 1.046 & $0.738-1.481$ & 0.186 & 0.802 \\
\hline
\end{tabular}

anastomosis and resultant lower incidence of anastomotic leaks, peritonitis or other bowel complications. In UKGOSOC, only $4.2 \%$ (91 out of 2192) of the cancer surgeries required a bowel resection.

Previous abdominal surgery was a significant predictor of Intraop complications probably due to intra-abdominal adhesions following the previous surgery. This is in keeping with results of a prospective multicentre Finnish study (FINHYST) of over 5000 hysterectomies for benign indications (Brummer et al, 2011), which found that prior laparotomy $(\mathrm{OR}=1.1)$ but not caesarean section or laparoscopy increased the risk of major complications. In the latter study, adhesiolysis during surgery was the strongest single risk factor $(\mathrm{OR}=2.4)$. In bowel surgery, previous three or 
more laparotomies have been found to increase risk of enterotomy by tenfold $(\mathrm{OR}=10.4)$ (Van Der Krabben et al, 2000). The other comorbidity that significantly increased Intra-op complication risk was diabetes $(\mathrm{OR}=2)$. While several studies have demonstrated the association of diabetes with increased Post-op morbidity (Pull et al, 2012; Gimenes et al, 2013; Fischer et al, 2014) this is the first study to demonstrate its effect specifically on Intra-op complications.

Intra-op CRs increased with surgical complexity with the highest rates for those procedures with an overall surgical complexity score of $>8$. In Aletti's study on ovarian cancer surgery as well as in the Australian study (Kondalsamy Chennakesavan et al, 2009), surgical complexity was found to be a significant predictor of overall morbidity. To capture complexity accurately in UKGOSOC, the surgical complexity scoring system for ovarian cancer developed by Aletti et al $(2007 \mathrm{a}, \mathrm{b})$ was modified to include procedures for all gynaecological cancers and stratified into five rather than the three originally described (low, intermediate and high) groups as preliminary analysis had demonstrated it to be a key predictor. Although a higher proportion of procedures were of low complexity in UKGOSOC, we feel that direct comparisons with the Australian study are difficult to make as surgical complexity was defined differently in the two studies. Surgery for ovarian cancer had the highest crude Intra-op CR at $8 \%$ which was double of that seen for the other gynaecological cancers. This is mainly influenced by the complexity of ovarian cancer surgery when compared with that for the others $(11 \%$ of ovarian cancer surgery had an overall complexity score of $>5$ when compared with $1-3 \%$ of the procedures for the other gynaecological malignancies).

When compared with Intra-op-CR, the Post-op-CR was much higher with approximately one in four surgeries having a Post-op complication. However, most of the complications were Grade II, which required medical therapy only as previously reported (Iyer et al, 2013). Vulval cancer $(\mathrm{OR}=2.4)$ when compared with other cancers and benign diagnosis posed the highest risk of developing a Post-op complication. Vulval cancer surgery also had the highest crude Post-op-CR (41.8\%) with wound infection/breakdown the commonest complication (32.9\%) followed by lymphocysts/lymphoedema (18.9\%). These rates were comparable to that reported in a recent review of complications of vulval cancer surgery where wound infection rates ranged from $17 \%$ to $39 \%$ and lymphoedema rates between $14 \%$ and $48 \%$ (Wills and Obermair, 2013). The incidence of intra-operative ureteric and bladder injury and postoperative bladder complications was highest for cervical cancer surgery when compared with other gynaecological cancers. However, this difference was not statistically significant (Supplementary Tables 7 and 8). This is likely to be related to the higher proportion of radical hysterectomies undertaken for cervical cancer. Overall, however, the rates are lower than those reported elsewhere, as in the United Kingdom, majority of radical hysterectomies are Type II rather than Type III as they are undertaken in patients with smaller tumours (Mota et al, 2008). Tumours of $>4 \mathrm{~cm}$ are more likely to be treated with chemo-radiation.

As previously reported, in studies comparing open $v s$ laparoscopic approaches for endometrial and cervical cancer surgery (Walker et al, 2009; Park et al, 2013), the latter reduced the likelihood of a Post-op complication in our series too. This is probably one of the main drivers for the increasing use of laparoscopic surgery in gynaecological oncology. Surgical complexity however was not a significant predictor of Post-op unlike Intraop complications. Instead, duration of surgery $(\mathrm{OR}=1.3)$ was significant. This has also been noted to increase the risk of Postoperative infections following total knee arthroplasty (Peersman et al, 2006).

In addition to being a significant predictor of Intra-op complications, diabetes $(\mathrm{OR}=1.6)$ was also found to be significant in predicting Post-op complications. In the Australian study, while diabetes was significant in univariable analysis, it was not found to be so in multivariable analysis (Kondalsamy Chennakesavan et al, 2009). However, studies in other specialties such as plastic surgery (breast reconstruction surgery) and orthopaedic surgery have shown diabetes to be a significant predictor of surgical complications, particularly wound infections (Pull et al, 2012; Liang et al, 2013; Fischer et al, 2014). Diabetes has also been found to increase the risk of Post-op complications following coronary artery bypass surgery (Gimenes et al, 2013). Our data indicate that the presence of any comorbidity $(\mathrm{OR}=1.3)$ predicted Post-op complications on multivariable analysis. Performance status as measured by ASA grade was significant only on univariable analysis. This is in contrast to the Australian study and Aletti's study where ASA grade was a significant independent predictor for overall morbidity (Aletti et al, 2007a; Kondalsamy Chennakesavan et al, 2009).

The 18-month prospective study was driven by the determination and desire of those involved to obtain robust data. National data collection in this manner without dedicated administrative support would not be feasible. For such data to be collected on a national scale, one of the options would be to incorporate some of the key audit fields into existing data sources coupled with routine central follow-up of patients using validated questionnaires. Despite the logistical issues, internal auditing using the system of clinician led data capture adopted in this study might still be preferable and acceptable to clinicians rather than external regulations that might be imposed in the foreseeable future (Hacker, 2011).

\section{CONCLUSIONS}

This the first large multicentre prospective study to investigate the morbidity associated with gynaecological oncology surgery. A set of robust complications data has been generated, which can be utilised for future benchmarking surgical practice. There are significant patient and surgical factors that influence risk, raising the need for risk-adjusted rates to compare outcomes.

\section{ACKNOWLEDGEMENTS}

The study was supported by researchers at the National Institute for Health Research, University College London Hospitals Biomedical Research Centre. We would like to thank the Eve appeal for their support of the study. We are very grateful to all the women who participated in this study and to all the medical, nursing and administrative staff who worked on UKGOSOC. In addition, we would like to thank the following members of the hospital teams who contributed to data collection: Sara Roberts, Philip Toon, Richard Peevor (Betsi Cadwaladr University Health Board), Charlie Chan, Janos Balega, Kavita Singh, Sudha Sundar, Ahmed Elattar, Esther Moss, Mary Wright (City Hospital Birmingham), Alta Viljoen (Cheltenham General Hospital), Branislav Potancok, Mohamed Ismail, Vivek Nama, Ruth Lomas, Cheryl Walke (East Kent University Hospital NHS Foundation Trust), Deborah Woods, Alison Garnham (Ipswich General Hospital), Ketan Gajjar, Deborah Parkinson (Royal Preston Hospital), Emma Arthur, Arnold Kruse (Royal Cornwall Hospital), and Kostas Doufekas (University College London Hospital).

\section{CONFLICT OF INTEREST}

The authors declare no conflict of interest. 


\section{REFERENCES}

http://www.connectingforhealth.nhs.uk/.

http://www.connectingforhealth.nhs.uk/systemsandservices/data/ clinicalcoding/codingstandards/opcs4/books.

Aletti G, Dowdy S, Podratz K, Cliby W (2007a) Relationship among surgical complexity, short-term morbidity, and overall survival in primary surgery for advanced ovarian cancer. Am J Obst Gynecol 197(6): 676.e1-e7.

Aletti GD, Santillan A, Eisenhauer EL, Hu J, Aletti G, Podratz KC, Bristow RE, Chi DS, Cliby WA (2007b) A new frontier for quality of care in gynecologic oncology surgery: multi-institutional assessment of short-term outcomes for ovarian cancer using a risk-adjusted model. Gynecol Oncol 107(1): 99-106.

Bridgewater B (2010) Cardiac registers: the adult cardiac surgery register. Heart 96(18): 1441-1443.

Brummer THI, Jalkanen J, Fraser J, Heikkinen A-M, Kauko M, Mäkinen J, Seppälä T, Sjöberg J, Tomás E, Härkki P (2011) FINHYST, a prospective study of 5279 hysterectomies: complications and their risk factors. Hum Reprod 26: 1741-1751.

Cockbain AJ, Carolan M, Berridge D, Toogood GJ (2012) Performance and quality indicators: the importance of accurate coding. Bull Royal Coll Surg Engl 94(2): 46-50.

Copeland G (2002) The POSSUM system of surgical audit. Arch Surg 137(1): $15-19$.

Das N, Talaat AS, Naik R, Lopes AD, Godfrey KA, Hatem MH, Edmondson RJ (2006) Risk adjusted surgical audit in gynaecological oncology: P-POSSUM does not predict outcome. Eur J Surg Oncol 32(10): 1135

Dindo D, Demartines N, Clavien PA (2004) Classification of surgical complications - a new proposal with evaluation in a cohort of 6336 patients and results of a survey. Ann Surg 240(2): 205-213.

Fischer JP, Tuggle CT, Au A, Kovach SJ (2014) A 30-day risk assessment of mastectomy alone compared to immediate breast reconstruction (IBR). J Plast Surg Hand Surg 0(0): 1-7.

Gimenes C, Barrile S, Martinelli B, Ronchi C, Arca E, Gimenes R, Okoshi M, Okoshi K (2013) Association of pre and intraoperative variables with postoperative complications in coronary artery bypass graft surgery. Rev Bras Cir Cardiovasc 28(4): 518.

Hacker NF (2011) Quality control in ovarian cancer surgery. Ann Oncol 22(Suppl 8): viii19.

Iyer R, Gentry Maharaj A, Nordin A, Liston R, Burnell M, Das N, Desai R, Gornall R, Beardmore Gray A, Hillaby K, Leeson S, Linder A, Lopes A, Meechan D, Mould T, Nevin J, Olaitan A, Rufford B, Ryan A, Shanbhag S, Thackeray A, Wood N, Reynolds K, Menon U (2013) Patient-reporting improves estimates of postoperative complication rates: a prospective cohort study in gynaecological oncology. Br J Cancer 109(3): 623.

Khuri SF (1998) The Department of Veterans Affairs' NSQIP: the first national, validated, outcome-based, risk-adjusted, and peer-controlled program for the measurement and enhancement of the quality of surgical care. Ann Surg 228(4): 491-507.

Kondalsamy Chennakesavan S, Bouman C, De Jong S, Sanday K, Nicklin J, Land R, Obermair A (2009) Clinical audit in gynecological cancer surgery: development of a risk scoring system to predict adverse events. Gynecol Oncol 115(3): 329.
Liang D, Zhimin H, Haijun X, Leizi C, Feng X (2013) Risk factors for postoperative wound complications of calcaneal fractures following plate fixation. Foot Ankle Int 34(9): 1238-1244.

Mota F, Vergote I, Trimbos JB, Amant F, Siddiqui N, Del Rio A, Verheijen R, Zola P (2008) Classification of radical hysterectomy adopted by the Gynecological Cancer Group of the European Organization for Research and Treatment of Cancer. Int J Gynecol Cancer 18(5): $1136-1138$.

National Bowel Cancer Audit Programme: Healthcare Quality Improvement Partnership (HQIP)Reports of the National Bowel Cancer Audit Project 2002-2006 http://www.hqip.org.uk/national-bowel-cancer-auditprogramme-nbocap.

Park J-Y, Kim D-Y, Kim J-H, Kim Y-M, Kim Y-T, Nam J-H (2013) Laparoscopic versus open radical hysterectomy in patients with stage IB2 and IIA2 cervical cancer. J Surg Oncol 108(1): 63-69.

Peersman G, Laskin R, Davis J, Peterson MGE, Richart T (2006) Prolonged operative time correlates with increased infection rate after total knee arthroplasty. HSS J 2(1): 70-72.

Pull T, Hosman AJ, Cohen DB, Schuetz M, Habil D, van L, van M (2012) A methodological systematic review on surgical site infections following spinal surgery: part 1: risk factors. Spine (Phila, $\mathrm{Pa} 1976)$ 37(24): 2017-2033.

RCOG (2012) Hospital Episode Statistics as a source of information on safety and quality in gynaecology to support revalidation.

Sokol D, Wilson J (2008) What is a surgical complication? World J Surg 32(6): 942-944.

Soliani P (1963) New classification of physical status. Anesthesiology 24: 111.

Van Der Krabben AA, Dijkstra FR, Nieuwenhuijzen M, Reijnen MM, Schaapveld M, Van Goor H (2000) Morbidity and mortality of inadvertent enterotomy during adhesiotomy. Br J Surg 87(4): 467-471.

van der Pas MHGM, Haglind E, Cuesta MA, Fürst A, Lacy AM, Hop WCJ, Bonjer HJ (2013) Laparoscopic versus open surgery for rectal cancer (COLOR II): short-term outcomes of a randomised, phase 3 trial. Lancet Oncol 14(3): 210-218.

Walker J, Piedmonte M, Spirtos N, Eisenkop S, Schlaerth J, Mannel R, Spiegel G, Barakat R, Pearl M, Sharma S (2009) Laparoscopy compared with laparotomy for comprehensive surgical staging of uterine cancer: Gynecologic Oncology Group Study LAP2. J Clin Oncol 27(32): 5331.

Westaby S, Archer N, Manning N, Adwani S, Grebenik C, Ormerod O, Pillai R, Wilson N (2007) Comparison of hospital episode statistics and central cardiac audit database in public reporting of congenital heart surgery mortality. BMJ 335(7623): 759.

WHO (1990) International Statistical Classification of Diseases and Related Health Problems 10th Revision.

Wills A, Obermair A (2013) A review of complications associated with the surgical treatment of vulvar cancer. Gynecol Oncol 131(2): 467.

This work is published under the standard license to publish agreement. After 12 months the work will become freely available and the license terms will switch to a Creative Commons AttributionNonCommercial-Share Alike 3.0 Unported License.

Supplementary Information accompanies this paper on British Journal of Cancer website (http://www.nature.com/bjc) 